\title{
Using point-of-care C-reactive protein to guide antibiotic prescribing for lower respiratory tract infections in elderly nursing home residents (UPCARE): study design of a cluster randomized controlled trial
}

Tjarda M. Boere ${ }^{1}$, Laura W. van Buul ${ }^{1 *}$, Rogier M. Hopstaken², Ruth B. Veenhuizen ${ }^{1}$, Maurits W. van Tulder ${ }^{3}$, Jochen W. L. Cals ${ }^{4}$, Theo J. M. Verheij, ${ }^{5,6}$ and Cees M. P. M. Hertogh ${ }^{1,5}$

\begin{abstract}
Background: Antibiotics are over-prescribed for lower respiratory tract infections (LRTI) in nursing home residents due to diagnostic uncertainty. Inappropriate antibiotic use is undesirable both on patient level, considering their exposure to side effects and drug interactions, and on societal level, given the development of antibiotic resistance. C-reactive protein (CRP) point-of-care testing (POCT) may be a promising diagnostic tool to reduce antibiotic prescribing for LRTI in nursing homes. The UPCARE study will evaluate whether the use of CRP POCT for suspected LRTI is (cost-) effective in reducing antibiotic prescribing in the nursing home setting.

Methods/design: A cluster randomized controlled trial will be conducted in eleven nursing homes in the Netherlands, with the nursing home as the unit of randomization. Residents with suspected LRTI who reside at a psychogeriatric, somatic, or geriatric rehabilitation ward are eligible for study participation. Nursing homes in the intervention group will provide care as usual with the possibility to use CRP POCT, and the control group will provide care as usual without CRP POCT for residents with (suspected) LRTI. Data will be collected from September 2018 for approximately 1.5 year, using case report forms that are integrated in the electronic patient record system. The primary study outcome is antibiotic prescribing for suspected LRTI at index consultation (yes/no).

Discussion: This is the first randomised trial to evaluate the effect of nursing home access to and training in the use of CRP POCT on antibiotic prescribing for LRTI, yielding high-level evidence and contributing to antibiotic stewardship in the nursing home setting. The relatively broad inclusion criteria and the pragmatic study design add to the applicability and generalizability of the study results.
\end{abstract}

Trial registration: Netherlands Trial Register, Trial NL5054. Registered 29 August 2018.

Keywords: Respiratory tract infection, Nursing home, Antibiotic prescribing, CRP, Point-of-care testing

\footnotetext{
* Correspondence: I.vanbuul@amsterdamumc.nl

${ }^{1}$ Department of General Practice \& Old Age Medicine, Amsterdam Public

Health Research Institute, Amsterdam University Medical Center, location VU

University Medical Center, Amsterdam, the Netherlands

Full list of author information is available at the end of the article
}

(c) The Author(s). 2020 Open Access This article is distributed under the terms of the Creative Commons Attribution 4.0 International License (http://creativecommons.org/licenses/by/4.0/), which permits unrestricted use, distribution, and reproduction in any medium, provided you give appropriate credit to the original author(s) and the source, provide a link to the Creative Commons license, and indicate if changes were made. The Creative Commons Public Domain Dedication waiver (http://creativecommons.org/publicdomain/zero/1.0/) applies to the data made available in this article, unless otherwise stated. 


\section{Background}

Lower respiratory tract infections (LRTI) such as pneumonia are common in nursing homes (NHs) [1]. In Dutch NHs in 2015, the incidence of suspected pneumonia was approximately 200 cases per 1000 residents, with a typical pattern of seasonal variation (i.e. winter peak, summer trough) [2]. NH residents are at increased risk of respiratory infections due to factors typical for this population, such as frailty and comorbidities. Also, the crowded nature of $\mathrm{NH}$ residence and frequent nursing staff-resident contact may facilitate the transmission of pathogens [1, 3-5]. The incidence of nursing homeacquired pneumonia (NHAP) can be up to tenfold of the incidence in elderly living in the community [1, 6-10]. Moreover, the severity and prognosis of NHAP is worse compared to pneumonia among elderly living in the community [11-13]. NH LRTI episodes may range from self-limiting viral infections, to severe NHAP requiring hospitalization or causing rapid death [3, 14-16].

An early diagnosis of NHAP enables prompt and appropriate management, decreases the risk of complications and mortality, and reduces overall health care costs [16-18]. Yet, physicians often find it difficult to estimate the severity and potential outcome of the LRTI episode $[19,20]$. Moreover, NH residents often have atypical clinical presentation, multi-morbidity, and a diminished ability to recall or describe symptoms (e.g. due to cognitive impairment). Diagnostic tools are often not available (e.g. chest X-ray) or applicable (e.g. sputum culture) in this setting $[3,5,17,21,22]$. Overall, diagnostic uncertainty often results in (empirical) antibiotic prescribing to be 'better safe than sorry'. This attitude towards antibiotic prescribing may be reinforced by external factors, such as (perceived) expectations of patients or family members towards antibiotic prescribing [23, 24].

Antibiotics are among the most commonly prescribed drugs in NHs, however, many of these prescriptions are inappropriate [25]. Inappropriate, or 'unjustified', antibiotic prescribing for LRTI in NH or care homes ranges from 25 to $98 \%$, according to studies from different settings and with different criteria for defining inappropriateness [21, 22, 26-29]. Overprescribing of antibiotics has possible negative consequences for the patient, such as drug interactions and side effects [21, 27]. At a societal level, overprescribing of antibiotics contributes to the development of antibiotic resistance, which decreases treatment possibilities for future LRTI [5].

C-reactive protein (CRP) point-of-care testing (POCT) is a promising tool to decrease the diagnostic uncertainty regarding suspected LRTI in the NH setting, and therefore decrease inappropriate antibiotic prescribing. CRP is a dynamic biomarker of the presence and severity of inflammation. CRP increases within four to 6 hours after the onset of an inflammatory reaction as well as rapidly decreases after its resolution (4 to 7 hours halftime, and 19 hours half-life) [30-32]. CRP POCT alongside the clinical signs and symptoms may provide the physician with valuable information for the treatment decision [33]. Studies in the general practice population showed CRP to be the strongest predictor of pneumonia, and that the reliability of the diagnosis improves when CRP is added to the evaluation of clinical signs and symptoms $[19,34]$. The introduction of CRP POCT in general practice has resulted in a significant and cost-effective reduction in antibiotic prescribing for LRTI in adults as well as in adults with underlying COPD, without negative consequences for clinical recovery [14, 35-37].

At present, CRP POCT is widely used in general practice in several countries, including the Netherlands. In the NH setting, however, (cost-) effectiveness of CRP POCT on antibiotic prescribing for LRTI has not yet been investigated. Consequently, CRP POCT is not commonly used in this setting. However, CRP-values may also have value in this setting. For instance, there is evidence that the CRP-level at index consultation predicts severity and outcome of pneumonia in the elderly population [38, 39].

This study protocol paper describes the design of a cluster Randomized Controlled Trial (RCT) that investigates whether the use of CRP POCT results in a safe reduction in antibiotic prescribing for $\mathrm{NH}$ residents with suspected LRTI. Other questions we aim to address are the extent to which CRP POCT values correlate with A) signs and symptoms in $\mathrm{NH}$ patients with suspected LRTI, and B) antibiotic treatment. Also, we will evaluate the cost-effectiveness and cost-benefit of the use of CRP POCT in the NH setting.

\section{Methods/design \\ Study design and population}

The UPCARE study design is a cluster RCT, with randomization at $\mathrm{NH}$ organization level. This randomization level was chosen because of our pragmatic trial design and in order to avoid spill-over effects. Data collection starts September 2018 and will, based on calculations of expected inclusion rate, last approximately 1.5 year. Eleven $\mathrm{NH}$ organizations across the Netherlands will participate in the study. A simple randomization procedure using Microsoft Office Excel 2016 software will be performed by the research team to allocate participating organizations to either the control or intervention group (1:1).

Dutch NHs typically have three types of specialized wards: somatic wards that accommodate physically disabled residents, psychogeriatric wards that accommodate residents with dementia, and geriatric rehabilitation wards. $\mathrm{NH}$ admission to one of these wards and the required level of care is determined by a standardized 
assessment performed by a government agency ("Centrum Indicatiestelling Zorg" (CIZ)). Unique to Dutch $\mathrm{NHs}$ is the employment of specialized 'elderly care physicians'. Other $\mathrm{NH}$ prescribers may include physicians with other specializations or general medical training, elderly care physicians in training, and nurse practitioners. Dutch NH medical care typically excludes the use of intravenous drugs, and hospital referrals are limited [40, 41].

The study population comprises $\mathrm{NH}$ residents from psychogeriatric, geriatric rehabilitation, or somatic wards, who are newly diagnosed with a 'suspected LRTI'. Patients are excluded if they receive palliative/terminal care with a restrictive antibiotic policy, if they do not wish to be treated with antibiotics, if they are using antibiotics (currently or in the past week), or if they have an infection other than the suspected LRTI (currently or in the past week).

\section{Sample size calculation}

Based on previous study data [40], we expect $15 \%$ less antibiotic prescriptions in the intervention group compared to the control group (i.e. $80 \%$ respectively $95 \%$ ). In order to detect this difference, with $80 \%$ power and at a $5 \%$ significance level, 146 cases would be required. If we randomize eleven $\mathrm{NH}$ organizations with an average number of 400 residents (cluster size) and with an intracluster correlation coefficient of 0.06 , the required number of cases is 671 [42].

The expected incidence rate of suspected LRTI is 3.5 cases per 1.000 resident-care weeks in NHs [2]. Based on previous study data, we expect that at most $10 \%$ of cases will not meet inclusion criteria and that $75 \%$ of eligible cases provide informed consent for study participation. This means that of all LRTI cases, approximately $70 \%$ can be included in the study, which translates into an expected 2.4 suspected LRTI per 1.000 resident-care weeks.

ln order to include 671 cases of LRTI in eleven organizations with an average number of 400 residents the study period totals to 1.5 year, with a small margin for potential suboptimal inclusion.

\section{Intervention}

In the intervention group, CRP POCT can be used onsite for residents with suspected LRTI in addition to usual care. The control group provides usual care without the possibility for CRP POCT. Usual care may in some cases include CRP-measurement via laboratory assessment, or, in rare cases, sputum culture or chest radiography.

CRP-measurement via laboratory assessment differs from CRP POCT with regard to the type of blood collection (venipuncture respectively finger prick), location (the blood is taken to an external lab respectively the measurement is performed on-site), time-to-results (hoursdays versus minutes), and potential frequency of measurements (once-twice a week on average versus 24/7).

During the trial, physicians in the intervention group decide on whether or not to use CRP POCT and, if performed, they consider the results alongside clinical features of the patient in their prescribing decision.

Prior to study commencement, the intervention group will receive two training sessions: 1 ) a medical training session and 2) a technical POCT training session.

\section{Medical training session}

Members of the research team will provide a medical training for medical doctors and nurse practitioners in the intervention group on the use and interpretation of CRP POCT for the diagnosis of LRTI. The contents of the training are based on the LRTI guideline for the $\mathrm{NH}$ setting (of the Dutch Association of Elderly Care Physicians and Social Geriatricians), and on extensive literature research. Topics include characteristics of the CRP POCT instrument (e.g. validity, reliability, and limitations), evidence and lessons learnt from the use of CRP POCT in general practice, and instructions specific to the NH setting. Specific instructions include the use of cut-off-values for antibiotic prescribing that are included in the LRTI guideline, i.e. a lower limit of $20 \mathrm{mg} / \mathrm{L}$ and an upper limit of $60 \mathrm{mg} / \mathrm{L}$. The latter is different from the cut-off-value in the general practice population (i.e. $100 \mathrm{mg} / \mathrm{L}$ ), and was based on a NH study that showed adequate discriminatory power for distinguishing pneumonia with this CRP-value [33].

\section{Technical POCT training session}

The POCT expert team from a non-commercial, EU accredited laboratory (Saltro diagnostic center, Utrecht) will provide the technical instructions to the intervention group of medical doctors and nurses who will perform CRP POCT during the trial. In each $\mathrm{NH}$ organization, a 'trainer' is appointed, who will train new employees during the study period. The technical training takes place after the medical training, within a period of 2 months. After the technical training until study commencement, the intervention group will have a run-in period to get used to CRP POCT in routine practice, varying from 1 week to 3 months per organization. The POCT expert team provides technical assistance during the trial and monitors quality throughout the study period.

\section{Technical features of CRP POCT}

The CRP POCT instrument that is used in this study (QuikRead go ${ }^{\circ}$, Orion Diagnostica Oy) has been shown to have adequate analytical accuracy and agreement with laboratory measurements $[43,44]$. The analyzer has a built-in self-check procedure that secures its correct use 
and correct results. In case of errors, the display will show a specific error notification.

The test principle relies on immunoturbidic measurement of turbidity changes in the sample due to the reaction of CRP with the reagent, i.e. monoclonal antihuman CRP F (ab) 2 fragments-coated microparticles.

The blood sample obtained by finger-prick, using a $20 \mu \mathrm{l}$ capillary tube, is dispensed into the cuvette, which hemolyzes the blood cells in the sample. Next, the cuvette is placed into the analyzer, which measures the hematocrit level before adding the reagent from the cap into the cuvette. With the reagent added, the microparticles bind to the CRP in the sample. The turbidity of the sample is then calculated using calibration information and with correction for the hematocrit level. In total, the CRP POCT measurement takes 2 to $4 \mathrm{~min}$.

\section{Data collection}

The period of data collection for each participant is 3 weeks. In this period, three case report forms (CRFs) are to be completed by the physician: at index consultation (T0), and at one (T1) and three (T2) weeks after index consultation. The CRFs are integrated into the electronic patient record system: eligibility criteria appear in an eligibility form if physicians diagnose a suspected LRTI. If eligible, CRFs are available electronically to be completed at due time points.

The T0 CRF contains questions on patient characteristics (principal diagnosis at $\mathrm{NH}$ admission, comorbid conditions, use of immunosuppressive medication, and recent surgery), signs and symptoms, performed diagnostics (CRP POCT and/or other), and antibiotic prescribing (yes/no, type). The T1 and T2 CRF include follow-up on patient recovery, changes in policy (additional diagnostics performed, hospital referral, and treatment changes). In addition, pharmacy data will be collected on total antibiotic prescribing in the $\mathrm{NH}$ during the study period. Figure 1 depicts the timeline of patient enrollment, intervention, and data collection.

\section{Informed consent procedure}

The informed consent procedure consists of two steps:

1) Written information is provided to either the patient or representative (depending on competence status, as judged by the physician), prior to study commencement or upon $\mathrm{NH}$ admission. At this time and throughout the study period, the patient/ representative is given the opportunity to opt-out. Opting-out is registered within the electronic patient record, which deactivates potential eligibility notifications. If opted-out, step two will not be initiated.

2) In case of a suspected LRTI, the physician contacts the patient/representative to ask for consent, which includes the opportunity to ask questions. In both groups, consent is asked for data collection. In the intervention group, consent is additionally asked for performing CRP POCT. An exceptional case is the situation in which the patient or the representative is not able to provide consent at the time of the diagnosis (e.g. if the patient is too ill or if the representative is not present): in that case, a physician can use CRP POCT as part of usual care if this is considered to support proper management. Consent is asked in retrospect (i.e. deferred consent), as soon as possible and at an appropriate moment, for data collection and potential future CRP POCT use. After the physician confirms within the CRF that the informed consent form is signed, data from the CRF are automatically sent to the research team in pseudonymized form via a secure web-portal.

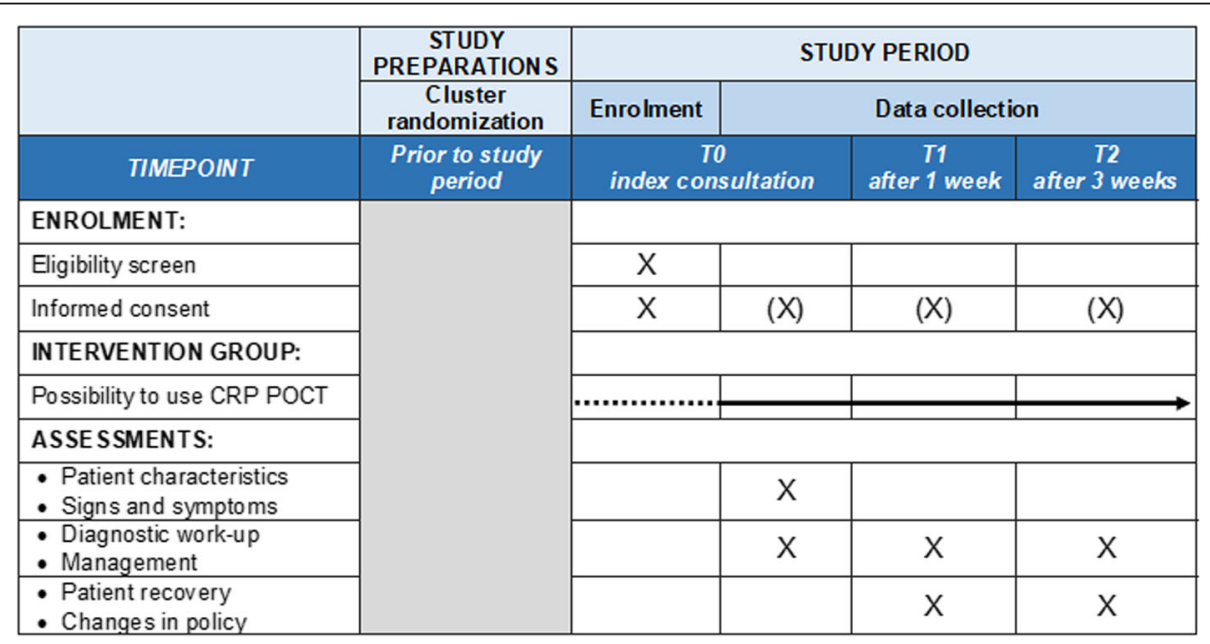

Fig. 1 schedule of patient enrollment, intervention, and data collection 


\section{Outcomes}

The primary study outcome is antibiotic prescribing for suspected LRTI at index consultation (yes/no). Secondary study outcomes include physician-reported recovery at one and 3 weeks after index consultation, use of additional diagnostics within 3 weeks after the index consultation (including repeated CRP measures), changes in treatment policy within 3 weeks after the index consultation, hospitalization, complications, (all-cause) mortality, and total antibiotic prescribing on the $\mathrm{NH}$ level.

Costs that will be included in the economic evaluation (health care perspective) are related to the use of CRP POCT, prescription of antibiotics, consultation by physicians in the $\mathrm{NH}$, additional diagnostic tests, hospital admissions and other health care utilization for LRTI and complications of LRTI treatment. Costs will be measured from the CRFs and valued using the guidelines of the National Health Care Institute [45].

\section{Data analysis}

The primary analysis will be intention-to-treat and will assess the effect of CRP POCT on antibiotic prescribing for suspected LRTI at index consultation. A three-level logistic regression model will be used to account for variation at the $\mathrm{NH} /$ physician/patient level. If there is no indication of random effects at the physician level, the model will be reduced to a two-level model. Multilevel regression modeling will similarly be used to compare secondary study outcomes between the two groups (linear or logistic, as appropriate). A second-order penalized quasi-likelihood estimation procedure will be applied.

Pharmacy data on total antibiotic prescribing will be explored descriptively, in order to describe the potential impact of adjusted antibiotic prescribing for LRTI on total antibiotic prescribing within intervention NHs, compared to control NHs. Total antibiotic prescriptions will be expressed per 1000 residents per year.

Data of patients in the intervention group will be used to explore potential relations between CRP POCT values and; 1 ) signs/symptoms in $\mathrm{NH}$ patients with suspected LRTI, and 2) antibiotic treatment. Multiple linear or logistic (as appropriate) regression modeling will be performed.

\section{Cost-effectiveness and cost-benefit analyses}

The cost-effectiveness analysis includes the percentage of antibiotic prescribing as outcome. A cost-benefit analysis, in which the reduction in antibiotic prescribing will be expressed in monetary terms, will also be performed. Missing data will be imputed in the cost-effectiveness analysis using multiple imputation techniques. Fully Conditional Specification and Predictive Mean Matching will be used to create ten complete data sets. Pooled estimates will be calculated according to Rubin's rules
[46]. We will calculate the mean differences for total and disaggregated costs and perform seemingly unrelated regression analyses, correcting for baseline characteristics and taking into account possible correlations between costs and effects. An incremental cost-effectiveness ratio will be calculated, with a corresponding cost-effectiveness plane. The cost difference and incremental costeffectiveness ratio will be Bootstrapped with 5000 replications. The probability of cost-effectiveness at different values of willingness-to-pay will be estimated and presented on a cost-effectiveness acceptability curve. We will conduct sensitivity analyses on uncertain parameters to evaluate the robustness of the results.

\section{Discussion}

This protocol paper describes the design of a cluster RCT to assess the effect of CRP POCT on antibiotic prescribing for LRTI in NHs. This is, to our best knowledge, the first large RCT to evaluate this topic in the $\mathrm{NH}$ setting. With this study, we aim to contribute to antibiotic stewardship efforts in the $\mathrm{NH}$ setting.

\section{Reflection on study design Study population}

We use broad inclusion criteria for the study population, for example we include patients from somatic, geriatric rehabilitation, and psychogeriatric wards. Research in the psychogeriatric population may be challenging, for instance with regard to obtaining informed consent. However, results of this study are especially important for this population as quick diagnosis and treatment initiation can be challenging (i.e. difficult clinical assessment) but essential given the vulnerability of this population $[5,16,17,21]$.

\section{Control group}

During the study we remain vigilant towards potential post-randomization recruitment bias: the control group might gradually or throughout the trial be less inclined to recruit patients, given the absence of the intervention $[14,20]$. We anticipate the need for incentives especially in the control group during the trial. Another phenomenon that may arise in the control group is the Hawthorne effect, that is, a shift towards more rational antibiotic prescribing because of the physician's awareness of being observed [29, 47].

\section{Data collection}

An anticipated strength of the study is the data collection method. The integration of the research tool in the electronic patient file ensures that data are collected in an efficient way. In addition, the use of automatic reminders and other technical support reduce the risk of missing data. 


\section{Informed consent procedure}

Reasons for exercising a deferred consent procedure stem from parallels seen in emergency research to this study, which we consider in emergency situations and in case the representative is unavailable $[48,49]$.

In case of certain emergency situations, CRP POCT could directly benefit patient care. For instance, CRP POCT might provide the physician with valuable information for the differential diagnosis between LRTI and congestive heart failure. Another consideration in asking consent during an emergency situation is that it might conflict with sufficient comprehension of study participation and with the principle of "evidencing a choice" [49].

Another situation that warrants deferred consent arises when the representative of an incapacitated resident is not readily available at index consultation. In that case, a requirement for prior consent could interfere with the time span within which CRP POCT is still worthwhile. Consequently, this subpopulation is unnecessarily disadvantaged in diagnostic possibilities - assuming the added value of CRP POCT that is seen in general practice and considering the higher burden of venipuncture compared to finger prick if CRP would instead be determined by laboratory assessment. Also, selection bias may appear if this subpopulation is more often excluded from the study because of difficulty in obtaining consent.

The alternative to ask consent pre-emptively was considered, however, this would require burdening a disproportionate number of residents with the question of consent, compared to those becoming eligible for participation. Moreover, as the period between consent and study participation could be lengthy the resident may not remember the choice for and extent of study participation.

\section{Reflection on study context Antibiotic stewardship in NHs}

In the Netherlands in recent years, antimicrobial resistance in different settings such as NHs has gained a more prominent place on the research and public health agenda. Antibiotic stewardship efforts are widely supported and developed for the $\mathrm{NH}$ setting by different parties. During the UPCARE study, it is important to monitor such activities as they might influence the primary outcome.

\section{LRTI guideline for the $\mathrm{NH}$ setting}

Around the start of data collection, a LRTI guideline was published for the $\mathrm{NH}$ setting by the Dutch Association of Elderly Care Physicians and Social Geriatricians. In this guideline, physicians are instructed to assess the CRP-level for patients who are moderately ill and who have certain clinical signs and symptoms that do not indicate LRTI unambiguously. In the guideline, CRP POCT is not specifically advised for CRP-measurement, as evidence for its (cost-) effectiveness is currently insufficient. With the UPCARE study we aim to address this knowledge gap.

\section{Pragmatic trial design}

We advise physicians and nurses in the intervention group on the possible use of CRP POCT and support them in this matter, but we do not use strict protocols on the use and interpretation of CRP POCT; physicians remain in charge of their diagnostic work-up and management decisions. This pragmatic design enables us to observe an effect that reflects daily practice. This increases the chance that our findings will be generalizable and widely applicable $[14,20]$. A potential pitfall of this approach is that the medical training session and other study preparations might not sufficiently incite behavioural change. Essential to the potentiality of a positive effect of the intervention is that physicians learn to trust CRP POCT findings and subsequently use these findings to adjust management when appropriate [20]. However, the use of CRP-measurements in general is not new and results from general practice are encouraging. Furthermore, all NHs will have a run-in period before study commencement to familiarise themselves with the use of CRP POCT (device and results). We will perform a process evaluation to explore the extent to which the intervention has been successfully implemented and used.

\section{Conclusion}

This is the first large RCT to evaluate CRP POCT for suspected LRTI in the NH setting. The broad inclusion criteria and pragmatic study design add to the applicability and generalizability of the study results. With this study we aim to contribute to antibiotic stewardship efforts in the NH setting.

\section{Abbreviations \\ CRF: Case Record Form; CRP POCT: C-Reactive Protein Point-Of-Care Test(ing), LRTI: Lower Respiratory Tract Infection; NH: Nursing Home; NHAP: Nursing} Home-Acquired Pneumonia; RCT: Randomized Controlled Trial

\section{Acknowledgements \\ We wish to thank Saltro diagnostic center for their contribution to the study preparations. We wish to thank Gerimedica (software supplier of the electronic patient file) for the development of the CRF. Also, we like to thank the participating nursing homes for their contribution to the study preparations.}

Authors' contributions

$\mathrm{LB}, \mathrm{CH}, \mathrm{TV}, \mathrm{RH}, \mathrm{MT}, \mathrm{RV}$, and JC were involved in the study conception and grant proposal. All authors contributed to the operationalization of the study design. TB drafted the manuscript. LB, CH, TV, RH, MT, JC and RV contributed to the final version of the manuscript. All authors have read and approved the manuscript. 


\section{Funding}

The UPCARE study is funded by The Netherlands Organisation for Health Research and Development (ZonMw, programme Antibiotic Resistance, grant number 541001 004). Orion Diagnostica and Saltro diagnostic center provide in total twenty CRP POCT instruments for the study. The funding bodies have no role in the design of the study, data collection, data analysis, interpretation, nor in writing the manuscript or authority over any of these activities.

\section{Availability of data and materials}

The datasets generated and/or analysed during the current study will be deposited in the repository DANS (EASY) after publication of the research results, within a maximum of 9 months post study termination. The dataset(s) involved will be anonymised/pseudonymised and can be accessed under restrictions.

\section{Ethics approval and consent to participate}

The research falls under the scope of the Medical Research Involving Human Subjects Act (WMO), therefore it was reviewed by an accredited Medical Research and Ethics Committee (MREC). The MREC of $\mathrm{VU}$ University medical center approved the study protocol under number NL62832.029.17, in compliance with the Helsinki Declaration and Dutch national legislation. The provided ethics approval from the MREC applies to all study sites. Prior to study commencement, the MREC gave formal approval for each study centre to participate in the study, and the Board of Directors of each study centre gave permission for execution of the study in their centre by signing a participation agreement

Written informed consent will be obtained from all study participants. The informed consent procedure consists of two steps:

1) Written information is provided to either the resident or representative (depending on competence status, as judged by the physician), prior to study commencement or upon $\mathrm{NH}$ admission. At this time and throughout the study period, the resident/representative is given the opportunity to optout. If opted-out, step two will not be initiated.

2) In case of a suspected LRTI, the physician contacts the patient/ representative to ask for consent, which includes the opportunity to ask questions. In both groups, consent is asked for data collection. In the intervention group, consent is additionally asked for performing CRP POCT. An exceptional case is the situation in which the patient or the representative is not able to provide consent at the time of the diagnosis (e.g. if the patient is too ill or if the representative is not present): in that case, a physician can use CRP POCT as part of usual care if this is considered to support proper management. Consent is asked in retrospect (i.e. deferred consent), as soon as possible and at an appropriate moment, for data collection and potential future CRP POCT use.

\section{Consent for publication}

Not applicable.

\section{Competing interests}

$\mathrm{TB}, \mathrm{LB}, \mathrm{MH}, \mathrm{RV}, \mathrm{TH}$ and $\mathrm{CH}$ have no competing interests to declare. $\mathrm{RH}$ is currently affiliated with "SHL-groep", which is a non-commercial organisation founded by general practitioners. SHL-groep provides diagnostic services for general practitioners.

\section{Author details}

'Department of General Practice \& Old Age Medicine, Amsterdam Public Health Research Institute, Amsterdam University Medical Center, location VU University Medical Center, Amsterdam, the Netherlands. ${ }^{2}$ Star-SHL diagnostic centers, Etten-Leur, the Netherlands. ${ }^{3}$ Department of Health Sciences, VU University, Amsterdam, the Netherlands. ${ }^{4}$ Department of Family Medicine, CAPHRI Care and Public Health Research Institute, Maastricht University, Maastricht, the Netherlands. ${ }^{5}$ National Institute for Public Health and the Environment (RIVM), Bilthoven, the Netherlands. ${ }^{6}$ Department of General Practice, Julius Centrum, University Medical Center Utrecht, Utrecht, the Netherlands.
Received: 14 November 2019 Accepted: 17 February 2020

Published online: 27 February 2020

\section{References}

1. Wojkowska-Mach J, Gryglewska B, Romaniszyn D, Natkaniec J, Pobiega M, Adamski $P$, et al. Age and other risk factors of pneumonia among residents of polish long-term care facilities. Int J Infect Dis. 2013;17(1):e37-43.

2. National Institute for Public Health and the Environment (RIVM). Surveillance netwerk infectieziekten in verpleeghuizen: Resultaten van wekelijkse surveillance, referentiecijfers 2011-2015. 2016.

3. Dhawan N, Pandya N, Khalili M, Bautista M, Duggal A, Bahl J, et al. Predictors of mortality for nursing home-acquired pneumonia: a systematic review. Biomed Res Int. 2015:2015:285983.

4. Garibaldi RA. Residential care and the elderly: the burden of infection. J Hosp Infect. 1999:43(Suppl):S9-18.

5. Lim CJ, Kong DC, Stuart RL. Reducing inappropriate antibiotic prescribing in the residential care setting: current perspectives. Clin Interv Aging. 2014;9: 165-77.

6. Hollaar VRY, van der Putten GJ, van der Maarel-Wierink CD, Bronkhorst EM, de Swart BJM, de Baat C, et al. Nursing home-acquired pneumonia, dysphagia and associated diseases in nursing home residents: a retrospective, cross-sectional study. Geriatr Nurs. 2017:38(5):437-41.

7. Muder RR. Pneumonia in residents of long-term care facilities: epidemiology, etiology, management, and prevention. Am J Med. 1998; 105(4):319-30.

8. Jackson ML, Neuzil KM, Thompson WW, Shay DK, Yu O, Hanson CA, et al. The burden of community-acquired pneumonia in seniors: results of a population-based study. Clin Infect Dis. 2004;39(11):1642-50.

9. Ochoa-Gondar O, Vila-Corcoles A, de Diego C, Arija V, Maxenchs M, Grive M et al. The burden of community-acquired pneumonia in the elderly: the Spanish EVAN-65 study. BMC Public Health. 2008;8:222.

10. Millett ER, Quint JK, Smeeth L, Daniel RM, Thomas SL. Incidence of community-acquired lower respiratory tract infections and pneumonia among older adults in the United Kingdom: a population-based study. PLoS One. 2013;8(9):e75131.

11. Ewig S, Klapdor B, Pletz MW, Rohde G, Schutte H, Schaberg T, et al. Nursinghome-acquired pneumonia in Germany: an 8-year prospective multicentre study. Thorax. 2012;67(2):132-8.

12. Liapikou A, Polverino E, Cilloniz C, Peyrani P, Ramirez J, Menendez R, et al. A worldwide perspective of nursing home-acquired pneumonia compared with community-acquired pneumonia. Respir Care. 2014;59(7):1078-85.

13. Ugajin M, Yamaki K, Hirasawa N, Kobayashi T, Yagi T. Prognostic value of severity indicators of nursing-home-acquired pneumonia versus community-acquired pneumonia in elderly patients. Clin Interv Aging. 2014; 9:267-74

14. Cals JW, Butler CC, Hopstaken RM, Hood K, Dinant GJ. Effect of point of care testing for $\mathrm{C}$ reactive protein and training in communication skills on antibiotic use in lower respiratory tract infections: cluster randomised trial. BMJ. 2009;338:b1374.

15. van der Steen JT, Mehr DR, Kruse RL, Sherman AK, Madsen RW, D'Agostino $\mathrm{RB}$, et al. Predictors of mortality for lower respiratory infections in nursing home residents with dementia were validated transnationally. J Clin Epidemiol. 2006;59(9):970-9.

16. Hollaar V, van der Maarel-Wierink C, van der Putten GJ, van der Sanden W, de Swart B, de Baat C. Defining characteristics and risk indicators for diagnosing nursing home-acquired pneumonia and aspiration pneumonia in nursing home residents, using the electronically-modified Delphi method. BMC Geriatr. 2016;16:60

17. Mills K, Graham AC, Winslow BT, Springer KL. Treatment of nursing homeacquired pneumonia. Am Fam Physician. 2009;79(11):976-82.

18. Loeb M, Carusone SC, Goeree R, Walter SD, Brazil K, Krueger P, et al. Effect of a clinical pathway to reduce hospitalizations in nursing home residents with pneumonia: a randomized controlled trial. JAMA. 2006;295(21):2503-10.

19. Hopstaken RM, Muris JW, Knottnerus JA, Kester AD, Rinkens PE, Dinant GJ. Contributions of symptoms, signs, erythrocyte sedimentation rate, and Creactive protein to a diagnosis of pneumonia in acute lower respiratory tract infection. Br J Gen Pract. 2003;53(490):358-64

20. Cals JW, Hopstaken RM, Butler CC, Hood K, Severens JL, Dinant GJ. Improving management of patients with acute cough by C-reactive protein point of care testing and communication training (IMPAC3T): study protoco of a cluster randomised controlled trial. BMC Fam Pract. 2007;8:15. 
21. Loeb M, Simor AE, Landry L, Walter S, McArthur M, Duffy J, et al. Antibiotic use in Ontario facilities that provide chronic care. J Gen Intern Med. 2001; 16(6):376-83.

22. Lim CJ, McLellan SC, Cheng AC, Culton JM, Parikh SN, Peleg AY, et al. Surveillance of infection burden in residential aged care facilities. Med J Aust. 2012;196(5):327-31.

23. van Buul LW, van der Steen JT, Doncker SM, Achterberg WP, Schellevis FG, Veenhuizen RB, et al. Factors influencing antibiotic prescribing in long-term care facilities: a qualitative in-depth study. BMC Geriatr. 2014;14:136.

24. Coenen S, Francis N, Kelly M, Hood K, Nuttall J, Little P, et al. Are patient views about antibiotics related to clinician perceptions, management and outcome? A multi-country study in outpatients with acute cough. PLoS One. 2013;8(10):e76691.

25. van Buul LW, van der Steen JT, Veenhuizen RB, Achterberg WP, Schellevis FG, Essink RT, et al. Antibiotic use and resistance in long term care facilities. J Am Med Dir Assoc. 2012;13(6):568.e1-13.

26. Pulia M, Kern M, Schwei RJ, Shah MN, Sampene E, Crnich CJ. Comparing appropriateness of antibiotics for nursing home residents by setting of prescription initiation: a cross-sectional analysis. Antimicrob Resist Infect Control. 2018;7:74

27. Olsho LE, Bertrand RM, Edwards AS, Hadden LS, Morefield GB, Hurd D, et al. Does adherence to the Loeb minimum criteria reduce antibiotic prescribing rates in nursing homes? J Am Med Dir Assoc. 2013;14(4):309.e1-7.

28. Vergidis P, Hamer DH, Meydani SN, Dallal GE, Barlam TF. Patterns of antimicrobial use for respiratory tract infections in older residents of longterm care facilities. J Am Geriatr Soc. 2011;59(6):1093-8.

29. van Buul LW, Veenhuizen RB, Achterberg WP, Schellevis FG, Essink RT, de Greeff SC, et al. Antibiotic prescribing in Dutch nursing homes: how appropriate is it? J Am Med Dir Assoc. 2015;16(3):229-37.

30. Young B, Gleeson M, Cripps AW. C-reactive protein: a critical review. Pathology. 1991;23(2):118-24.

31. Pepys MB, Hirschfield GM. C-reactive protein: a critical update. J Clin Invest. 2003;111(12):1805-12.

32. Clyne B, Olshaker JS. The C-reactive protein. J Emerg Med. 1999;17(6):1019-25.

33. Nouvenne A, Ticinesi A, Folesani G, Cerundolo N, Prati B, Morelli I, et al. The association of serum procalcitonin and high-sensitivity $C$-reactive protein with pneumonia in elderly multimorbid patients with respiratory symptoms: retrospective cohort study. BMC Geriatr. 2016;16:16.

34. van Vugt SF, Broekhuizen BD, Lammens C, Zuithoff NP, de Jong PA, Coenen S, et al. Use of serum $C$ reactive protein and procalcitonin concentrations in addition to symptoms and signs to predict pneumonia in patients presenting to primary care with acute cough: diagnostic study. BMJ. 2013;346:f2450.

35. Cals JW, Ament AJ, Hood K, Butler CC, Hopstaken RM, Wassink GF, et al. Creactive protein point of care testing and physician communication skills training for lower respiratory tract infections in general practice: economic evaluation of a cluster randomized trial. J Eval Clin Pract. 2011;17(6):1059-69.

36. Little P, Stuart B, Francis N, Douglas E, Tonkin-Crine S, Anthierens S, et al. Effects of internet-based training on antibiotic prescribing rates for acute respiratory-tract infections: a multinational, cluster, randomised, factorial, controlled trial. Lancet. 2013;382(9899):1175-82.

37. Butler CC, Gillespie D, White P, Bates J, Lowe R, Thomas-Jones E, et al. Creactive protein testing to guide antibiotic prescribing for COPD exacerbations. N Engl J Med. 2019;381(2):111-20.

38. Arinzon Z, Peisakh A, Schrire S, Berner Y. C-reactive protein (CRP): an important diagnostic and prognostic tool in nursing-home-associated pneumonia. Arch Gerontol Geriatr. 2011;53(3):364-9.

39. Porfyridis I, Georgiadis G, Vogazianos P, Mitis G, Georgiou A. C-reactive protein, procalcitonin, clinical pulmonary infection score, and pneumonia severity scores in nursing home acquired pneumonia. Respir Care. 2014; 59(4):574-81.

40. van Buul LW, van der Steen JT, Achterberg WP, Schellevis FG, Essink RT, de Greeff SC, et al. Effect of tailored antibiotic stewardship programmes on the appropriateness of antibiotic prescribing in nursing homes. J Antimicrob Chemother. 2015;70(7):2153-62

41. Verbeek H, Zwakhalen SM, van Rossum E, Ambergen T, Kempen Gl, Hamers JP. Small-scale, homelike facilities versus regular psychogeriatric nursing home wards: a cross-sectional study into residents' characteristics. BMC Health Serv Res. 2010;10:30

42. Campbell MK, Fayers PM, Grimshaw JM. Determinants of the intracluster correlation coefficient in cluster randomized trials: the case of implementation research. Clin Trials. 2005;2(2):99-107.
43. Minnaard MC, van de Pol AC, Broekhuizen BD, Verheij TJ, Hopstaken RM, van Delft $S$, et al. Analytical performance, agreement and user-friendliness of five C-reactive protein point-of-care tests. Scand J Clin Lab Invest. 2013; 73(8):627-34.

44. Seamark DA, Backhouse SN, Powell R. Field-testing and validation in a primary care setting of a point-of-care test for C-reactive protein. Ann Clin Biochem. 2003;40(Pt 2):178-80.

45. National Health Care Institute (Zorginstituut Nederland). Richtlijn voor het uitvoeren van economische evaluaties in de gezondheidszorg, 2016. 2017.

46. Rubin DB. Multiple imputation for nonresponse in surveys: John Wiley \& Sons; 2004.

47. Cals JW, Chappin FH, Hopstaken RM, van Leeuwen ME, Hood K, Butler CC et al. C-reactive protein point-of-care testing for lower respiratory tract infections: a qualitative evaluation of experiences by GPs. Fam Pract. 2010; 27(2):212-8.

48. Harron K, Woolfall K, Dwan K, Gamble C, Mok Q, Ramnarayan P, et al. Deferred consent for randomized controlled trials in emergency care settings. Pediatrics. 2015;136(5):e1316-22.

49. Jansen TC, Kompanje EJ, Bakker J. Deferred proxy consent in emergency critical care research: ethically valid and practically feasible. Crit Care Med. 2009;37(1 Suppl):S65-8.

\section{Publisher's Note}

Springer Nature remains neutral with regard to jurisdictional claims in published maps and institutional affiliations.
Ready to submit your research? Choose BMC and benefit from:

- fast, convenient online submission

- thorough peer review by experienced researchers in your field

- rapid publication on acceptance

- support for research data, including large and complex data types

- gold Open Access which fosters wider collaboration and increased citations

- maximum visibility for your research: over $100 \mathrm{M}$ website views per year

At $\mathrm{BMC}$, research is always in progress.

Learn more biomedcentral.com/submissions 